\title{
The army nurse practitioner transition to practice program
}

\author{
Edward Yackel ${ }^{1}$, Daniel Blaz ${ }^{2}$, Brad Franklin*3, Grace Northrup $^{4}$ \\ ${ }^{1}$ U.S Army Medical Command, Fort Sam Houston, United States \\ ${ }^{2}$ U.S Army Central, Shaw Air Force Base, United States \\ ${ }^{3}$ Brooke Army Medical Center, Fort Sam Houston, United States \\ ${ }^{4}$ Fort Belvoir Community Hospital, Fort Belvoir, United States
}

Received: May 6, 2018

DOI: $10.5430 /$ jnep.v8n12p71
Accepted: July 23, 2018

Online Published: August 12, 2018

\begin{abstract}
The Army Nurse Corps established a Transition to Practice Program (TPP) to better position Army NPs to excel in complex clinical environments. The purpose of the TPP was to provide a structured educational transition to clinical practice for new graduate Advance Practice Registered Nurses (APRNs). A small pilot (test-of-change) was conducted at two Army hospitals. The results of the pilot indicated that length of time was the most important factor for the program. Findings during this pilot implementation were limited, but provide great insight into revising the program in order to produce skilled and confident Army APRNs.
\end{abstract}

Key Words: Nurse practitioner, Advanced practice registered nurses, Transition to practice, Army

\section{INTRODUCTION}

The complexity of our nation's healthcare environment requires the highest level of scientific knowledge and practice expertise to ensure that care rendered is high quality, safe, cost effective, and evidenced based. The Institute of Medicine, Joint Commission, and other professional authorities have called for transformation of educational programs that prepare today's Advanced Practice Registered Nurse professionals. ${ }^{[1]}$ In 2004, the American Association of Colleges of Nursing (AACN) adopted a position statement supporting the Doctorate of Nursing Practice (DNP) degree and distinguishes the DNP degree as the entry level of practice for all Nurse Practitioners (NPs). ${ }^{[2]}$ Despite academic rigor and the number of clinical hours required for the DNP degree, new graduates are challenged with the swift transition to au- tonomous practice with minimal orientation following graduation. ${ }^{[3]}$ Given the complexity of our healthcare system today and variations between nursing programs, post-graduate transition to clinical practice is emphasized to ensure competency, readiness, and mentorship while promoting autonomy and confidence. ${ }^{[4]}$

\subsection{Military healthcare}

Military healthcare has transformed over the past two decades and Advanced Practice Registered Nurses (APRNs), specifically NPs have been an instrumental part of the transformation. NPs are a vital component of the U.S. Army healthcare team that provide comprehensive ambulatory, acute, and primary healthcare to support individuals, families and communities. ${ }^{[5,6]}$ NPs also provide essential medical

\footnotetext{
* Correspondence: Brad Franklin, Lieutenant Colonel, U.S. Army; Email: brad.franklin@ usuhs.edu; Address: 3551 Roger Brooke Dr, Bldg 3642, Fort Sam Houston, TX 78234, United States.
} 
care in the combat environment rendering care in a variety of deployed and sometimes austere settings. Therefore, military NPs must have expanded clinical knowledge when compared with their civilian counterparts. Trauma management, treatment of post-traumatic stress disorder, and operational and tropical medicine are some examples. In addition, military NPs must be able to adapt and overcome the ambiguity and complexity of a changing battlefield. ${ }^{[7]}$ The healthcare environment within Army Medicine has also experienced change. Adjusting to continuous deployments, recruiting qualified NPs, maximizing Soldier readiness, preparing NPs to be a ready medical force, enhancing access to care, and adjusting to financial constraints are some of examples of the changes occurring within Army Medicine. In 2008, the Army Nurse Corps established the Transition to Practice Program (TPP) to better prepare Army NPs to adapt to a clinical environment of high operational tempo healthcare operations. ${ }^{[8]}$ The Army Medical Command (MEDCOM) codified the TPP in official Army policy.

\subsection{Nurse practitioner transition to practice}

There is a paucity of evidence in regards to outcomes of NP transition to practice programs, formal orientation pathways, NP residencies and/or fellowship programs. ${ }^{[9]}$ The Institute of Medicine identified a significant need for healthcare organizations to take steps in establishing a transition to practice program for NPs in order to provide evolution of their clinical practice. ${ }^{[1]}$ Army NPs continue to meet the demands of primary and acute care, but also rise to the challenge of executing care within the deployed or austere environment. ${ }^{[10]}$ Fitzpatrick and Gripshover identified transition shock that occurs with new NPs that leads to anxiety and performance issues; therefore, employers are establishing specialized orientation and transition programs to create a conduit for confident practice. ${ }^{[11]}$ This initial transition year for a new NP is a critical component to development and an integral part of building confidence in clinical skills, role identification, and overall job satisfaction. ${ }^{[3]}$ Hart and Macnee investigated how well new NPs were prepared for their clinical practice and found that only $10 \%$ of NPs felt well prepared, $38 \%$ felt generally prepared, and $51 \%$ were minimally prepared for clinical practice. ${ }^{[12]}$ Diagnostic testing, such as x-ray and EKG interpretation, suturing, and other minor office procedures were areas NPs felt least prepared. ${ }^{[12]}$ Sargent and Olmedo performed a needs assessment of new NP graduates through surveys and focus groups to identify learning needs and clinical practice autonomy. ${ }^{[3]}$ In looking at "confidence" they found that $80 \%$ of the new NPs perceived themselves as being very confident in their role within primary care, but in regards to "preparedness" only 55\% felt somewhat prepared. ${ }^{[3]}$
Over the past decade NPs have become more diverse within their professional role placing a greater emphasis on skill development/acquisition and experience. ${ }^{[12,13]}$ Given this, NP practice has matured beyond primary care to include full scope practice and management of urgent and chronic conditions. Furfari, Rosenthal, Tad-y, Wolfe, and Glasheen surveyed NPs who participated in an inpatient fellowship program and found that $100 \%$ of the fellows felt very unprepared to care for patients in that setting. ${ }^{[14]}$ Likewise, Schofield, and McComiskey established a nine month inpatient critical care NP fellowship in order to further refine and build on NPs didactic knowledge as a new graduate. ${ }^{[4]}$ In the pre-fellowship survey it was found that new NPs had a mean pre-score of little experience in critical care, no experience in procedural competence, and low scores in simulation exercises. ${ }^{[4]}$ Ensuring adequate and appropriate transition to the NP role is critical to the future success and integration of the new NP graduate. ${ }^{[15]}$ Hart and Bowen surveyed more recent graduates of NP programs and found 39\% of NPs felt generally well prepared and $43 \%$ felt somewhat prepared for clinical practice. ${ }^{[15]}$ In regards to completing a NP residency program, $32 \%$ were somewhat interested in participating in a program while $40 \%$ were extremely interested in a residency program.

Poor transition experiences of NPs have resulted in job dissatisfaction, lack of confidence and uncertainty, high employee turnover, isolation, and frustration. ${ }^{[4,13]}$ Barnes surveyed 352 NPs at a National NP Conference and found that only $33 \%$ of those participants received any type of formal orientation process. ${ }^{[13]}$ Barnes also determined that the length of time one served as a registered nurse did not show a significant relationship with the NP role. There are many different factors in our healthcare system today that pressure NPs to quickly assimilate to their new role as a healthcare provider. Scholtz, King, and Kolb developed a NP transition program and found NPs had increased networking and referral engagement, less job turnover, were able to established best practices, and improve inter-professional collaboration. ${ }^{[16]}$ Development of a transition program for novice NPs allows for a concentrated focus and deepening of clinical knowledge and skills that fill the gap between academia and current practice.

\subsection{Army nurse practitioners transition to practice}

Each year the Army selects approximately seven to ten Army Nurse Corps officers for advanced schooling to become Family NPs. There are approximately 162 military Family NPs on active duty within the Army today and are dispersed between 32 Army military treatment facilities (MTFs). Army NPs enter the military through several graduate pathways (Directly from the civilian sector, Army funded to attend 
the Uniformed Services University or a civilian School of Choice, and Army Nurse Corps officers who select to selffund their NP education). Variation in graduate pathways create challenges when designing one program to orient NPs to the requirements of working within military healthcare (i.e. electronic medical records system, multiple healthcare system applications, physical profiling of service members, Army readiness requirements and Army regulations). Like their civilian counterparts, new graduate Army NPs may also struggle with uncertainty, anxiety, frustration, self-doubt, lack of confidence and inter-professional support.

The purpose of the Army TPP is to provide a structured transition to clinical practice for APRNs who are new graduates from an accredited college or university. ${ }^{[8]}$ The TPP provides an opportunity for the new NP to familiarize themselves with Army healthcare and the MTF to which they are assigned. The TPP also applies to experienced NPs (civilian and military) who have had a break in practicing within the Army Medical System and APRNs who are experienced, but new to the military. The program goals, objectives, and framework are to facilitate the preceptee's successful transition to practice role within the Army Medical System while establishing clinical practice confidence and refinement of diagnostic skills (see Table 1 and Figure 1).

Table 1. MEDCOM 40-52 program objectives

\begin{tabular}{l} 
Key Objectives \\
\hline 1. Facilitate and support acquisition of skills, knowledge, electronic medical record proficiency, and use of other pertinent computer \\
applications. \\
2. Facilitate and refine critical thinking and procedural skills. \\
3. Develop leadership components that are imperative within the Military Healthcare System. \\
4. Facilitate interdisciplinary collaboration, synchronize the prioritization and management of patient healthcare needs. \\
5. Use resource systems for optimal management of evidenced-based patient healthcare (e.g., Clinical Practice Guidelines [CPG's]). \\
6. Document successful completion of the transition program to ensure full scope practice.
\end{tabular}

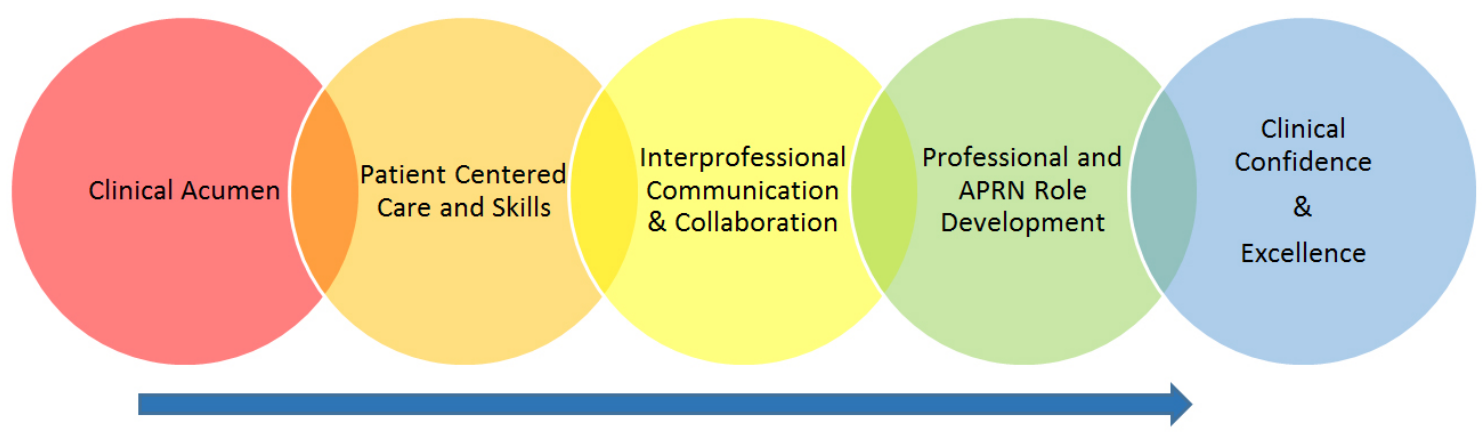

Figure 1. TPP Framework

\section{MeTHODS}

A systematic evidence-based approach was employed to revise the TPP. A Tiger Team consisting of APRNs (civilian and military) representing family practice, academia, nursing research, psychology, midwifery, nurse anesthesia, and clinical nurse specialists (CNS) collaborated over email and telephone consultation for over a year. A literature review and gap analysis were conducted, purpose and objectives were delineated and approved by Army Nurse Corps leadership. Revisions to the TPP were made, evaluated, and further refined, and finally a TPP policy was submitted for publication. Additionally, several sub-working groups were created to work on specific portions of the TPP which inPublished by Sciedu Press cluded the literature review, refinement of forms, publication, and change package groups.

\section{RESUlts}

The literature review was limited to journal articles published from 2011-2017 using the following search terms: Transition to Practice; Nurse Practitioner Residency/Fellowship/APRN. Search of the Uniformed School Universities Power Search Database yielded 40 articles while CINAHL had 9 and EMBASE had 14 to review. Duplicate articles were excluded and a literature synthesis completed.

A gap analysis conducted by the Tiger Team included a re- 
view of the 2012 version of the TPP (MEDCOM 40-52) and applicable Army and MEDCOM policies and regulations. A baseline survey of 76 Family Nurse Practitioners (FNP) and Psychiatric Mental Health Nurse Practitioners (PMHNP) using convenience sampling was also conducted.

Gaps in the 2012 version of the TPP were identified (see Table 2). As part of the review, it was discovered that Nurse Midwives and Nurse Anesthetists were purposefully excluded from the TPP because their graduate degree pro- grams had "residency" requirements. Of note, the 2012 version of the TPP only applied to FNPs and PMHNPs; therefore, these were the APRNs surveyed in order to determine the efficacy of the program "as written". Survey results indicated that there was a delay of between 15-16 weeks from graduating from a Master's/DNP program and starting clinical practice. The survey revealed $20 \%$ of respondents did not participate in a "residency" program and a majority of FNPs and PMHNPs felt "moderately comfortable" with the residency training they received (79\% and $73 \%)$.

Table 2. Gaps in the 2012 version of MEDCOM 40-52

Gaps from Previous TPP Version
1. No recognition of the Doctorate of Nursing Practice
2. Exclusion of civilian APRN and CNS communities
3. Prescriptive length of the TPP regardless of the knowledge and experience level of the individual
4. No central administrative authority for execution and oversight of the TPP
5. Outdated cost and accounting guidance to allot for time spent in the TPP

The literature review, gap analysis, and baseline survey informed how the Tiger Team approached revisions to the TPP. Revisions to the TPP were addressed by sub-working groups that met asynchronously to facilitate rapid re-write of the regulation. Significant work was undertaken by a forms subworking group to standardize, pilot, and publish revised TPP forms such as clinical rotation guides. A small pilot (testof-change) was conducted at two Army MTFs using draft versions of clinical rotation guides. The results of the pilot indicated that length of time was the most important factor for the program and recommendations were made to add, delete, or modify rotational guides and other forms. As a result of piloting, 19 forms were eliminated from the TPP. Publishing the piloted and revised forms also required that the forms sub-working group synchronize and coordinate their efforts with other MEDCOM stakeholders and entities such as the Information Technology Directorate of the Defense Health Agency. Working with this Directorate was necessary to ensure new TPP forms were electronically available worldwide using an automated forms program.

\section{Discussion}

The Tiger Team charged with revising the TPP employed a systematic approach to change a policy with system-wide implications. The revised TPP recognizes the DNP, enables civilian APRN and CNS communities to participate in the program, allows the program length to be tailored to the learner's needs and experience level, places administrative authority for the program under the direction of the Chief Nurse Executive, and updates cost and accounting guidance.
In addition, the revisions to the TPP forms and work flow algorithms were added to assist involved stakeholders in executing their roles. These algorithms were essential as they provided critical guidance for the preceptee as they delineate the tasks that must completed to start and finish the TPP. Finally, two key sub-working groups (the publication and change package) were instrumental in launching the TPP. The publication working group reformatted the TPP into Army policy (MEDCOM 40-52) to meet Army requirements for publishing official regulations (awaiting final signature). The change package working group crafted an information paper, a PowerPoint presentation to senior leaders and stakeholders, and developed marketing tools to promote the re-launching of the program, ultimately influencing Army program and policy. Upon final signature of the updated policy, the TPP should be implemented, data collected, and further refined. Inter-Service (Army, Air-Force, Navy, and DHA) collaboration should occur to standardize a TPP for all APRNs. Creation of a data repository, establishment of a TPP portal, and applying for Practice Transition Accreditation are future recommendations.

\section{Implications for practice}

Transition to practice programs have expanded across the country as organizations strive to recruit, retain, and orient novice nurse practitioner into their organizations. Strategically, the expansion of TPPs indicates that nurse practitioner training programs are not adequately preparing their graduates for initial autonomous practice. ${ }^{[10]}$ Factors that may contribute to this are the complexity of the healthcare en- 
vironment, emerging healthcare issues and technology, and established curriculum may not provide students with all the tools necessary for practice within program timelines (two-three years). ${ }^{[15,17]}$ The Army TPP is not a "one size fits all" program. The program allows each organization to tailor a TPP that meets the needs of the novice NP within the framework of the TPP regulation and fills the knowledge gap between training program and effective clinical practice. The Army program is easily modifiable and can be replicated across organizations to orient new nurse practitioners to independent clinical practice. TPPs have the potential to improve the transition experience, develop evidence-based recommendations, create a pool of clinical mentors, and a platform for improving NP retention and satisfaction. ${ }^{[13,15]}$

\section{Conclusion}

The complexity of our nation's healthcare environment requires the highest level of scientific knowledge and practice expertise. The TPP offers a standardized approach for ARPNs to transition into practice based on individual learn- ing needs. Transition into a fast-paced and broad scope clinical practice within the Army as a novice APRN is a demanding and challenging event. It is vital to foster growth and development of a new APRN and provide clinical tools for experienced APRNs who are returning to clinical practice. Findings during this pilot implementation were limited, but provide great insight into fine tuning the program in order to produce skilled and confident Army APRNs. The overall goal of any transition program is producing a highly competent, compassionate, and self-confident APRNs who are committed to the organization and their patients.

\section{CONFLiCTS OF INTEREST Disclosure}

The authors declare that there are no conflicts of interest. The view(s) expressed herein are those of the author(s) and do not reflect the official policy or position of Brooke Army Medical Center, the U.S. Army Medical Department, the U.S. Army Office of the Surgeon General, the Department of the Army, the Department of the Air Force and Department of Defense or the U.S. Government.

\section{REFERENCES}

[1] Institute of Medicine. The future of nursing: Leading change, advancing health. Washington D.C.: The National Academies of Press; 2010.

[2] American Association of Colleges of Nursing. The essentials of doctoral education for advanced nursing practice. 2006. Available from: http://www.aacn.nche.edu/publications/pos ition/DNPEssentials.pdf

[3] Sargent L, Olmedo M. Meeting the needs of new-graduate nurse practitioners. Journal of Nursing Administration. 2013; 43(11): 603-610. PMid:24153203 https://doi.org/10.1097/01.NNA.0000434 506.77052.d2

[4] Schofield DL, McComiskey CA. Postgraduate nurse practitioner critical care fellowship: Design, implementation, and outcomes at a tertiary medical center. The Journal for Nurse Practitioners. 2015; 11(3): e19. https://doi.org/10.1016/j.nurpra.2014.11.001

[5] Franklin BE, Carr KV, Padden DL. Self-assessment of trauma competencies among army family nurse practitioners. Military medicine. 2008; 173(8).

[6] U. S. Army. Family nurse practitioner (66P). 2014. Available from: https://www. goarmy. com/careers-and-jobs/amedd-cat egories/nurse-corps-jobs/family-nurse-practitioner. html

[7] Dargis J, Horne T, Tillman-Ortiz S, et al. Expanding the role of the nurse practitioner in the deployed setting. Mil Med. 2006; 171(8): 770-773. https://doi.org/10.7205/MILMED . 171.8.770

[8] United States Army Medical Command. MEDCOM Regulation 4052. In: Command USAM, ed. Fort Sam Houston, TX. 2018.

[9] Bush CT, Lowery B. Postgraduate Nurse Practitioner Education: Impact on Job Satisfaction. The Journal for Nurse Practitioners. 2016; 12(4): 226-234. https://doi.org/10.1016/j . nurpra.2 015.11 .018
[10] Faraz A. Novice nurse practitioner workforce transition into primary care: A literature review. Vol 38. Los Angeles, CA: SAGE Publications; 2016; 1531-1545 p.

[11] Fitzpatrick S, Gripshover J. Expert nurse to novice nurse practitioner: The journey and how to improve the process. Journal for Nurse Practitioners. 2016; 12(10): e419-e421. https://doi.org/10.1016/ j.nurpra.2016.05.012

[12] Hart AM, Macnee CL. How well are nurse practitioners prepared for practice: Results of a 2004 questionnaire study. Journal of the American Academy of Nurse Practitioners. 2007; 19(1): 35-42. PMid:17214866 https://doi.org/10.1111/j.1745-7599.20 $06.00191 . x$

[13] Barnes H. Exploring the factors that influence nurse practitioner role transition. The Journal for Nurse Practitioners. 2015; 11(2): 178183. PMid:25685113 https://doi.org/10.1016/j.nurpra.2 014.11 .004

[14] Furfari K, Rosenthal L, Tad-y D, et al. Nurse practitioners as inpatient providers: A hospital medicine fellowship program. Journal for Nurse Practitioners. 2014; 10(6): 425-429. https ://doi.org/10 $.1016 / j$.nurpra. 2014.03.022

[15] Hart AM, Bowen A. New nurse practitioners' perceptions of preparedness for and transition into practice. Journal for Nurse Practitioners. 2016; 12(8): 545-552. https://doi.org/10.1016/j.nurpra.2 016.04 .018

[16] Scholtz A, King K, Kolb S. The care model of the future: Supporting APRNs through an innovative transition to practice program. Journal of Pediatric Health Care. 2014; 28(3): 276-279. PMid:24433923 https://doi.org/10.1016/j.pedhc. 2013.11.002

[17] Le D. Meeting the Needs of New Graduate Nurse Practitioners. Journal of Doctoral Nursing Practice. 2016; 9(1): 88. https: //doi.org/10.1891/2380-9418.9.1.88 